\title{
Time allocations for different activities in the fiddler crab Tubuca rosea (Tweedie, 1937) (Brachyura, Ocypodidae)
}

\author{
Fahmida Wazed Tina (D). Kanitta Keeratipattarakarn •
} Mullica Jaroensutasinee $\cdot$ Krisanadej Jaroensutasinee

FW Tina (Corresponding author)

Faculty of Science and Technology, Nakhon Si Thammarat Rajabhat University, Nakhon Si Thammarat 80280, Thailand. email: fahmidatina14@gmail.com

\author{
K Keeratipattarakarn - M Jaroensutasinee - K \\ Jaroensutasinee
}

Centre of Excellence for Ecoinformatics, School of Science, Walailak University, Nakhon Si Thammarat 80161, Thailand.

Received: December 03, 2018 - Revised: December 30, 2018 • Accepted: December 30, 2018

\begin{abstract}
Investigating the time activity budgets of fiddler crabs is very important to determine the effects of sex and body size on allocating time for different activities. Few previous studies investigated the effects of sex and body size on time allocations in underground mating species. This study determines the effects of sex, size and their interaction on time allocations in a surface mating species (Tubuca rosea (Tweedie, 1937)). The surface activities of large and small, male and female crabs were video recorded. Afterwards time allocations for various activities (e.g., feeding, standing (vigilance), walking, inside burrows, grooming, burrowing, mating, and for males only, fighting and claw-waving) were calculated. All crabs spent most of their time on feeding than on other activities. Smaller crabs spent more time being vigilant, whereas larger crabs spent more time on courtship displays (grooming, and waving), and fighting. Between sexes, females spent more time standing, but less time on walking and grooming than males. Predation risk, reproductive maturation, breeding/non-breeding season, and energy conservation could be important factors for shaping time allocations in $T$. rosea.
\end{abstract}

Keywords: activity budgets, courtship display, feeding, mating, vigilance

\section{Introduction}

In animals, males and females show different activities and they allocate time differently for different activities based on their requirements. For example, feeding activity is very important for animals to gain energy for various activities, especially for reproduction. On the other hand, reproductive activity is important to produce the offspring, and this activity shapes the feeding activity of animals (Schoener 1971). Animals would allocate less time for feeding and more time for reproductive activity when the chances for mate selection and reproductive success are higher, and it may happen during breeding season. On the contrary, animals would allocate more time for feeding and less time for reproduction when the chances of reproductive success are lower, and it can be observed during non-breeding season (Schoener 1971; Caravello and Cameron 1991).

Sex, body size and parental investment are important factors that influence the behavioural decisions in animals. In general, sexual selection is stronger in males than in females (Trivers 1972). Males allocate more time than females for mate attraction and territorial defense. However, smaller-sized males are less attractive to females in many animals including fiddler crabs (e.g., mottled sculpin (Cottus bairdi (Girard, 1850)), striped triplefin (Forsterygion varium (Forster, 1801)), redlip blenny (Ophioblennius atlanticus (Valenciennes, 1836)), topi (Damaliscus lunatus (Burchell, 1823)), puku (Kobus vardoni Livingstone, 1857), and fiddler crabs Tubuca paradussumieri (Bott, 1973), Austruca annulipes (H. Milne Edwards, 1837), and Austruca mjoebergi (Rathbun, 1924)) (Brown 1981; Thompson 1986; Côte and Hunte 1989; Balmford et al 1992; Backwell and Passmore 1996; Jaroensutasinee and Jaroensutasinee 2003; Callander et al 2012), thus, they tend to spend less time on courtship displays (Tina et al 2016) as it increases the expenditure of time and energy without any benefit (Callander et al 2012). Furthermore, energy demand for gamete production is different between males and females. As females produce larger and more costly eggs compared to smaller and less costly sperms produced by males, thus, females demand higher energy than males (Trivers 1972; Brunton 1988). Therefore, individuals from different sex and size groups should allocate their time differently for different activities based on their requirements, and it is very important to know how animals allocate their time for different activities. Using observation method is the best way to explore animal behaviours, especially for animals in groups (Altmann 1974). 
Fiddler crabs are an excellent model for studying time allocations as they are highly social animals and show numerous social behaviours (Caravello and Cameron 1991; Weis and Weis 2004; Tina et al 2016). Moreover, their behaviours can be easily observed and recorded under natural conditions (Mokhlesi et al 2011; Tina et al 2016). Until now, only two studies investigated the effects of sex and size on time allocation in Leptuca panacea Novak \& Salmon, 1974 and A. annulipes (Caraello and Cameron 1991; Tina et al 2016). Both of these species are underground mating species in where males build the breeding burrows, and females select males based on their burrow qualities and incubate eggs inside those male burrows (Caravello and Cameron 1991; Backwell and Passmore 1996). Whereas, no research has been conducted to determine the effects of sex, body size and their interaction on time allocations of a surface mating species, in where females build their breeding burrows and incubate eggs inside their burrows (Christy and Salmon 1984; deRivera and Vehrencamp 2001). In this study, we are aiming to test the effects of sex, body size and their interaction on time allocations of Tubuca rosea (Tweedie, 1937) for the first time. T. rosea is a surface mating species (Murai et al 1996; Tina et al 2018) and is widely distributed in the mangroves in western coast of Malaya.

\section{Materials and methods}

Study site

We investigated the surface activities of $T$. rosea inside mangrove vegetation at Tammalang Port, Satun Province (6³2'06.96"N 10004'16.73"E), southern Thailand during dry season (April to June, 2017). T. rosea reproduces throughout the year but mostly from July to October and from January to March (Sen and Homechaudhuri 2015). This T. rosea population occupied an area of $450 \mathrm{~m}^{2}$. This study was conducted during neap low tide, and between 9:00 am and 1:00 pm.

\section{Behaviour observation}

We selected randomly 177 crabs regarding of their sex and size (97 females (large: 53, small: 44), and 80 males (large: 39, small: 41)), and video recorded their activities using a Panasonic DMC-GX1 camera. Each day, video recordings were conducted in an unbiased manner, so that both size classes and sexes were recorded equally or nearly.

The larger and smaller crabs were divided based on the carapace width (smaller: 6.78-14.00 mm, larger 14.01-22.80 $\mathrm{mm})$. Each crab was video recorded for ten minutes. Afterwards, the crab was caught to measure its carapace width using digital Vernier callipers to the nearest $0.01 \mathrm{~mm}$. All videos were watched, and surface activities were classified as: feeding, standing (vigilance), inside burrows, mating, walking, grooming, burrowing, fighting, and waving. Fighting and waving were observed only in males. A few numbers of crabs (5 females and 4 males) showed surface mating, and all of them were larger than $16 \mathrm{~mm}$. The amount of time each crab spent on each activity was analysed, and the percentage of time was calculated.

\section{Statistical analysis}

Parametric statistics were used when normality or other assumptions of parametric tests were met. The percentage data of time allocation were arcsine transformed (in degrees) (Sokal and Rohlf 1981). One-way ANOVA tests with posthoc Bonferroni corrections were used to determine the differences in time allocation in males and females separately. A Multivariate Analysis of Variance (MANOVA) test was used to analyse the effects of sex, size and their interaction on time allocation. In MANOVA, male activities only (fighting and waving) were not included. We used $t$-tests to determine the differences in (1) carapace width between mating and nonmating crabs, and (2) time spent on fighting and waving between smaller and larger males. Data were reported as mean values \pm standard error (SE). All significance tests were considered statistically significant at $P<0.05$.

\section{Results}

\section{Crab body size and surface mating}

The crabs who showed surface mating was larger in size than the crabs who did not show surface mating (mating crabs: $19.60 \pm 0.81 \mathrm{~cm}$, non-mating crabs: $13.47 \pm 0.34 \mathrm{~cm}$, $\left.t_{175}=3.84, P<0.001\right)$.

\section{Time allocation for surface activities in males and in females}

Time allocation in males, as well as in females, differed significantly among the activities (One-way ANOVA: males: $F_{8,711}=192.32, P<0.001$; females: $\left.F_{6,672}=398.83, P<0.001\right)$. Both sexes spent more time on feeding than on other activities $(P<0.001)$ (Figure 1a, b).

\section{Sex, body size, and time allocation for surface activities}

Multivariate analysis of variance showed that sex, size, and the interaction of sex and size had effects on time allocation (sex: Wilks' Lambda $=0.71, F_{7,167}=9.62, P<0.001$; size: Wilks' Lambda $=0.74, F_{7,167}=8.43, P<0.001$; sex $\times$ size: Wilks' Lambda $\left.=0.81, F_{7,167}=5.40, P<0.001\right)$. Two-way ANOVA showed that in the case of spending time on standing, females and smaller crabs spent more time on standing than males and larger crabs, respectively, but sex $\times$ size did not show any effect (sex: $F_{1,173}=11.70, P<0.005$; size: $F_{1,173}=$ 23.05, $P<0.001$; sex $\times$ size: $F_{1,173}=0.53$, $n s$; Figure $\left.2 \mathrm{a}\right)$. In grooming, males groomed more than females, and larger crabs 
groomed more than smaller crabs, but sex $\times$ size did not show any effect (sex: $F_{1,173}=47.57, P<0.001$; size: $F_{1,173}=17.21$, $P<0.001$; sex $\times$ size: $F_{1,173}=2.21$, ns; Figure $2 b$ ). In the case of walking, females spent less time on walking than males, whereas size and sex $\times$ size, did not show any effect (sex: $F_{1,173}$ $=7.97, P<0.01$; size: $F_{1,173}=2.62, n s$; sex $\times$ size: $F_{1,173}=0.21$, $n s$; Figure 2c). In surface mating, only larger crabs showed surface mating, but sex and sex $\times$ size did not show any effect (sex: $F_{1,173}=0.53$, ns; size: $F_{1,173}=7.76, P<0.01$; sex $\times$ size: $F_{1,173}=0.53, n s ;$ Figure $2 \mathrm{~d}$ ). In the case of spending time inside burrows, sex and body size did not show any effect, whereas sex $\times$ size had an effect (sex: $F_{1,173}=0.09, n s$; size: $F_{1,173}=$ $0.18, n s ;$ sex $\times$ size: $F_{1,173}=5.77, P<0.05$; Figure 2e). During spending time in feeding and burrowing, sex, size and sex $\times$ size did not show any effect (feeding: sex: $F_{1,173}=0.61, n s$; size: $F_{1,173}=0.35, n s$; sex $\times$ size: $F_{1,173}=1.59, n s$; burrowing: sex: $F_{1,173}=1.67, n s ;$ size: $F_{1,173}=0.11, n s ;$ sex $\times$ size: $F_{1,173}=$ $0.78, n s ;$ Figure $2 \mathrm{f}, \mathrm{g}$ ). For male activities only (fighting and waving), larger males spent more time on fighting and waving than smaller ones (fighting: $t_{78}=2.56, P<0.05$; waving: $t_{78}=$ $3.85, P<0.001$; Figure $2 \mathrm{~h}, \mathrm{i})$.

(a)

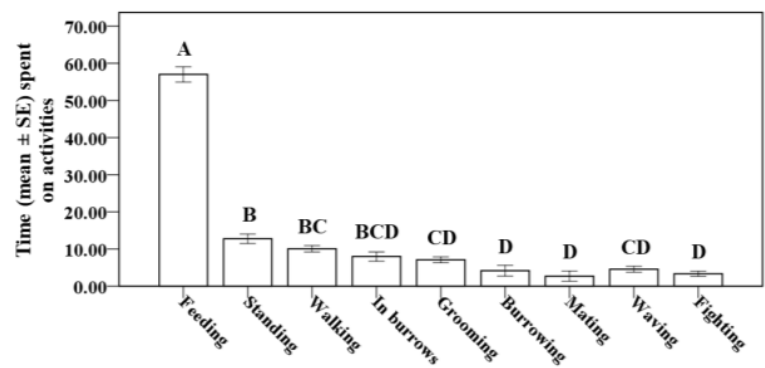

(b)

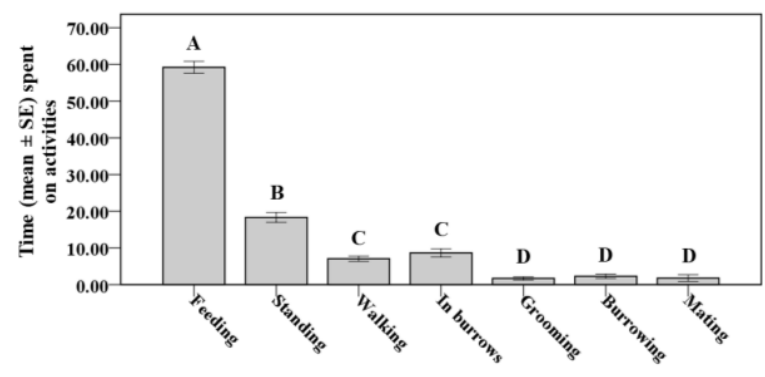

Figure 1 Time spent (\%) (arcsine transformed, degrees) on surface activities in Tubuca rosea males (a, white bars) and females (b, gray bars); upper-case letters indicate the mean differences $(P<0.05)$ among the activities.

\section{Discussion}

In fiddler crabs, males and females from underground mating species (i.e., L. panacea, A. annulipes) spend most of their time on feeding, and their time allocation for feeding is not different between sexes (Caravello and Cameron 1987; Tina et al 2016). Their findings support our finding, and all of these studies show that both underground and surface mating species spend most of their time on feeding. Females spend more time on feeding to get energy for producing eggs, as well as for increasing the number of egg clutches (Salmon and Hyatt 1983), whereas males spend more time on feeding to get energy for courtship displays (Milner et al 2012). Time allocation for feeding was not different between small and large crabs. Similar result was observed in L. panacea from State Park, Galveston, Texas, whereas, smaller crabs of $L$. panacea from East Lagoon, Galveston, Texas and $A$. annulipes from southern Thailand spent more time on feeding than larger crabs (Caravello and Cameron 1987; Tina et al 2016). These findings indicate that size affects feeding behaviour differently in different species or populations, and it may happen due to differences in resource availability, or levels of competition and predation risk among species or habitats (discussed in Caravello and Cameron 1991).

Smaller crabs spent more time on standing than larger ones, and females spent more time on standing and less time on walking than males. Animals tend to stay vigilant mainly for two reasons- (1) to detect predators and/or to minimize the predation risk (Lima and Dill 1990), and (2) to conserve energy (discussed by Cowlishaw 1998). Normally smaller fiddler crabs have more predation risk than larger ones (MacIntosh 1979), and thus, they might stay vigilant more than larger ones. However, in the case of underground mating species (L. panacea; A. annulipes), small and large crabs spent similar amount of time on standing. The reason behind this different finding could be the predation risk of the populations. Smaller crabs from a population with higher predation risk might spend more time on being vigilant compared to the larger ones due to their higher predation risk. In females, more standing and less walking probably reflects energy conservation. As locomotion is energetically costly (Dasilva 1992), thus, reducing movement may help the females to conserve energy. Females demand high energy to produce eggs and incubate egg masses. Moreover, in surface mating species, females construct breeding burrows for egg incubation that is not the case in underground mating species. On the other hand, males walked more compared to the females probably due to mate searching. In surface mating species (e.g., Gelasimus vocans, and T. rosea) (Christy and Salmon 1984; Murai et al 1996), mate searching by males is common (Christy and Salmon 1984).

$T$. rosea males spent more time on grooming than females. Similar result was observed in A. annulipes males (Tina et al 2016). There are two possible reasons behind this. First, males groom more in order to make their major claws as bright as possible because females tend to choose males with brighter claws (Bergey 2007). Second, males possibly require less energy to wave a claw covered with less mud compared to one with more mud. 
(a)

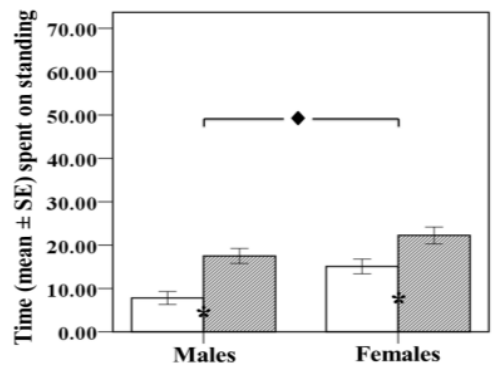

(d)

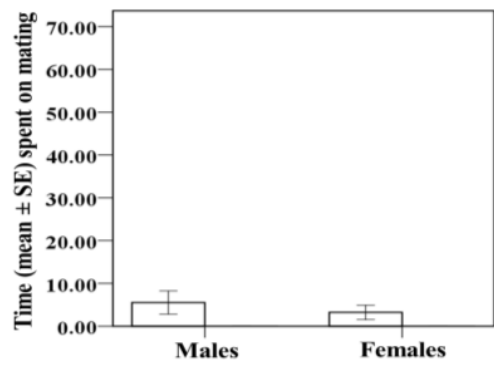

(g)

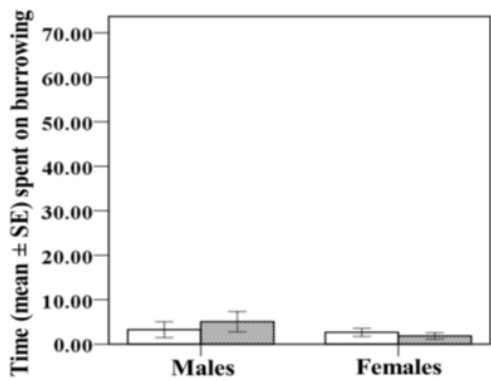

(b)

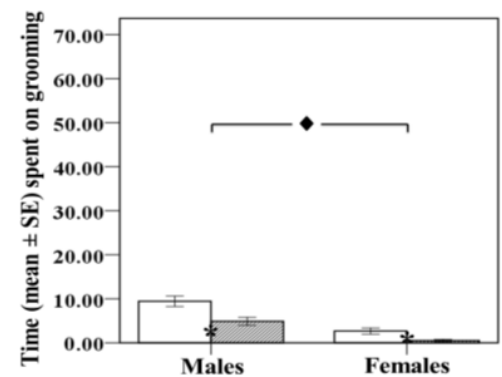

(e)

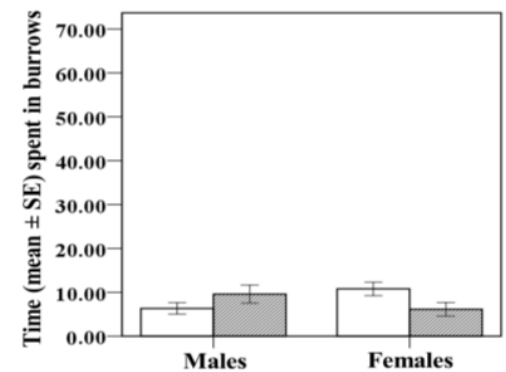

(h)

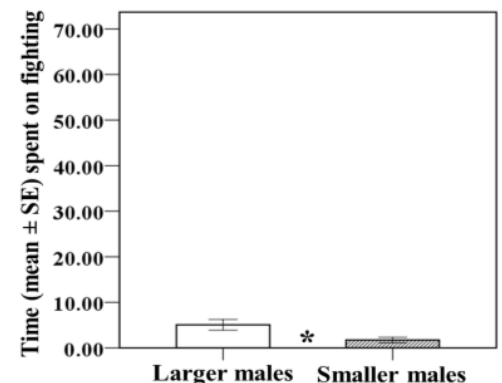

(c)

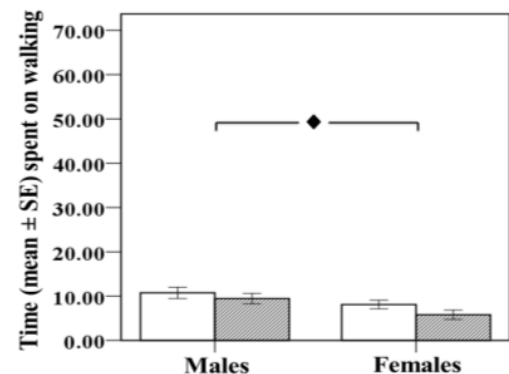

(f)

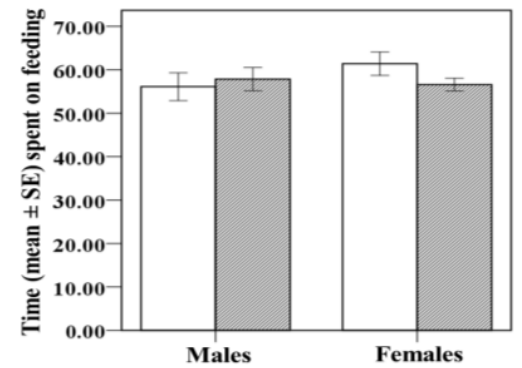

(i)

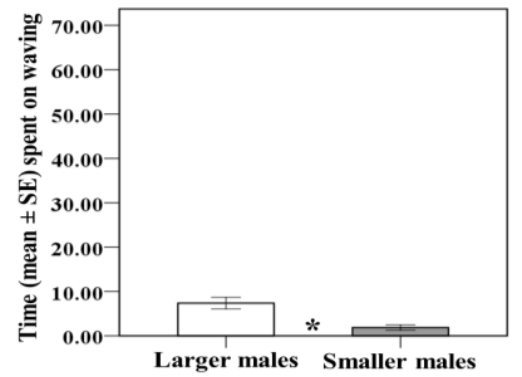

Figure 2 Time spent (\%) (arcsine transformed, degrees) of large (white bars) and small (black and white, diagonally stripped bars) Tubuca rosea (Tweedie, 1937) males and females on their activities: a, standing; b, grooming; c, walking; d, mating; e, in burrows; f, feeding; g, burrowing; h, fighting; and i, waving; ' $\$$ ' indicates differences between sexes, and '*' indicates differences between sizes.

Smaller males spent less time on courtship displays (i.e., grooming, and waving) than larger males, because smaller males are not large enough to attract females. In fiddler crabs, male body size acts as a mate selection criterion, and females tend to select larger males for mating (Backwell and Passmore 1996; Jaroensutasinee and Jaroensutasinee 2003; Callander et al 2012), because larger males copulate for longer time than smaller males (Jaroensutasinee and Jaroensutasinee 2003). Thus, T. rosea smaller males groom and wave less, as they have less chance of selection by females. Smaller males also spent less time on fighting than larger males. Similar result was observed in the case of the $A$. annulipes (Tina et al 2016). Usually, larger crabs in a population are involved more in fighting than smaller crabs, as larger males are strong enough to take over other males' burrows through fighting than smaller ones (Jaroensutasinee and Tantichodok 2002; Tina et al 2015). In crabs, digging a new burrow is more energetically costly than renovating a burrow (Hyatt and Salmon 1978).
It was observed that only large-sized crabs $(>16 \mathrm{~mm}$ carapace width) were involved in surface mating. Our finding supports some previous findings. Sen and Homechaudhuri (2015) observed that $T$. rosea females attained sexual maturity when they were $\geq 10 \mathrm{~mm}$ in carapace width, and Crane (1975) observed ovigerous females of $16 \mathrm{~mm}$ in carapace width. Furthermore, Murai et al (1996) observed that T. rosea males and females that were involved in mating were at least $16 \mathrm{~mm}$ in carapace width. We also observed that a few numbers of crabs were involved in mating. The reason behind this could be that this study was conducted during the time (April-June) when $T$. rosea show lowest reproductive activity (Sen and Homechaudhuri 2015). Another important point is that less involvement in mating activity could be linked with higher feeding activity that we have observed in this study. Usually during non-breeding season, crabs spend more time on feeding or gaining energy (Caravello and Cameron 1991), as they are not interested in reproductive activity during that time. 


\section{Conclusions}

This study shows how sex, body size and their interaction affect the time allocations of a surface mating fiddler crab species (T. rosea). Both sexes (small and large) allocate most of their time for feeding to gain energy. Larger crabs spent more time on courtship display than smaller crabs due to their reproductive maturity or higher reproductive demands. Smaller crabs spent more time on standing than larger crabs, probably due to their higher predation risk. Females spent more time on standing than males, probably for conserving energy, as their parental investment is higher than males. This study determines how $T$. rosea males and females of different sizes allocate their time differently for different activities and offers several possible explanations for observed differences. Further study should investigate the effects of breeding season and predation risk on time activity budget of fiddler crabs.

\section{Acknowledgements}

We sincerely thank Mr. Jonh Barker for improving the English text of this manuscript. The authors are grateful to the Centre of Excellence for Ecoinformatics and Postdoctoral fellowship (Grant No. 59701, F. W. Tina), Walailak University, NSTDA (Grant No. P-17-50973), and Faculty of Science and Technology, Nakhon Si Thammarat Rajabhat University for financial supports.

\section{References}

Altmann J (1974) Observational study of behavior: sampling methods. Behaviour 49: 227-267.

Backwell PRY, Passmore NI (1996) Time constraints and multiple choice criteria in the sampling behaviour and mate choice of the fiddler crab, Uca annulipes. Behavioral Ecology and Sociobiology 38:407-416.

Balmford A, Rosser AM, Albon SD (1992) Correlates of female choice in resource-defending antelope. Behavioral Ecology and Sociobiology 31:107-114.

Bergey LL (2007) Behavioral ecology and population biology in populations of fiddler crabs, Uca pugnax (Smith), on the New Jersey coast. Rutgers University, New Jersey-Newark.

Brown L (1981) Patterns of female choice in mottled sculpins (Cottidae, Teleostei). Animal Behaviour 29:373-382.

Brunton DH (1988) Sexual differences in reproductive effort: timeactivity budgets of monogamous killdeer, Charadrius vociferous. Animal Behaviour 36:705-711.

Callander S, Jennions MD, Backwell PRY (2012) The effect of claw size and wave rate on female choice in a fiddler crab. J Ethol 30:151155.

Caravello HE, Cameron GN (1987) Foraging time allocation in relation to sex by the Gulf coast fiddler crab (Uca panacea). Oecologia 72:123-126.
Caravello HE, Cameron GN (1991) Time activity budgets of the Gulf coast fiddler crab (Uca panacea). American Midland Maturalist 126:403-407.

Christy JH, Salmon M (1984) Ecology and evolution of mating systems of fiddler crabs (genus Uca). Biological Reviews 59:483509.

Côte IM, Hunte W (1989) Male and female mate choice in the redlip blenny: why bigger is better. Animal Behaviour 38:78-88.

Cowlishaw G (1998). The role of vigilance in the survival and reproductive strategies of desert baboons. Behaviour 135:431-452.

Crane J (1975) Fiddler crabs of the world. Ocypodidae: genus Uca. Princeton University Press, Princeton, NJ.

Dasilva GL (1992) The western black-and-white colobus as a lowenergy strategist: activity budgets, energy expenditure and energy intake. Journal of Animal Ecology 61:79-91.

deRivera CE, Vehrencamp SL (2001) Male versus female mate searching in fiddler crabs: a comparative analysis. Behavioral Ecology 12:182-191.

Hyatt GW, Salmon M (1978) Combat in the fiddler crabs Uca pugilator and $U$. pugnax: a quantitative analysis. Behaviour 65:182211.

Jaroensutasinee M, Jaroensutasinee K (2003) Male body size influences female choice and male-male competition in the fiddler crab, Uca paradussumieri Bott, 1973 (Decapoda, Brachyura, Ocypodidae). Crustaceana 76:177-186.

Jaroensutasinee M, Tantichodok P (2002) Effects of size and residency on fighting outcomes in the fiddler crab, Uca vocans hesperiae (Decapoda, Brachyura, Ocypodidae). Crustaceana 75:1107-1117.

Kim TW, Kim KW, Srygley RB, Choe JC (2004) Semilunar courtship rhythm of the fiddler crab Uca lactea in a habitat with great tidal variation. Journal of Ethology 1:63-68.

Lima SL, Dill LM (1990) Behavioral decisions under the risk of predation: a review and prospectus. Canadian Journal of Zoology 68:619-640.

MacIntosh DJ (1979) Predation of fiddler crabs (Uca spp.) in estuarine mangroves. In: Srivastaba PBL (ed) Proceeding symposium on mangrove and estuarine vegetation in southeast Asia, $25^{\text {th }}-28^{\text {th }}$ April, 1978. Serdang, Selangor, Malaysia. Biotrop. Spec. Publ. Series, pp 101-110.

Milner RNC, Jennions MD, Backwell PRY (2012) Keeping up appearances: male fiddler crabs wave faster in a crowd. Biology Letters 8:176-178.

Mokhlesi A, Kamrani E, Backwell P, Sajjadi M (2011) Study on the behaviour of two fiddler crabs, Uca sindensis and Uca annulipes (Decapoda: Ocypodidae), in Bandar Abbas, Iran. Journal of the Marine Biological Association of the United Kingdom 91:245-249.

Murai M, Goshima S, Kawai K, Yong HS (1996) Pair formation in the burrows of the fiddler crab Uca rosea (Decapoda: Ocypodidae). Journal of Crustacean Biology 16:522-528.

Salmon M, Hyatt GW (1983) Spatial and temporal aspects of reproduction in North Carolina fiddler crabs (Uca pugilator Bosc). Journal of Experimental Marine Biology and Ecology 70:21-43.

Schoener TW (1971) Theory of feeding strategies. Annual Review of Ecology and Systematics 2: 369-404. 
Sen S, Homechaudhuri S (2015) Spatial distribution and population structure of fiddler crabs in an Indian Sundarban mangrove. Scientia Marina 79:79-88.

Sokal RR, Rohlf FJ (1981) Biometry: the principles and practice of statistics in biological research. W. H. Freeman, San Francisco.

Thompson S (1986) Male spawning success and female mate choice in the mottled triplefin, Forsterygion varium (Pisces: Tripterygiidae). Animal Behaviour 34:580-589

Tina FW, Jaroensutasinee M, Jaroensutasinee K (2015) Effects of body size, resident status and handedness on fighting behaviour of the fiddler crab, Uca bengali Crane, 1975. Crustaceana 88:775-789.

Tina FW, Jaroensutasinee M, Jaroensutasinee K (2016) Sex and size affecting time allocations for activities in Uca annulipes (H. Milne Edwards, 1837). Crustaceana 89:759-773.
Tina FW, Jaroensutasinee M, Keeratipattarakarn K, Jaroensutasinee K (2018) Surface mating influences chimney/burrow characteristics of Uca rosea (Tweedie, 1937) (Brachyura, Ocypodidae) in southern Thailand. Crustaceana 91:311-320.

Trivers R (1972) Parental investment and sexual selection. In: Campbell B (ed) Sexual selection and the descent of man. Aldine Press, Chicago, pp 1871-1971.

Weis JS, Weis P (2004) Behavior of four species of fiddler crabs, genus $U c a$, in southeast Sulawesi, Indonesia. Hydrobiologia 523:4758 . 